\title{
DIAPHRAGMATIC MYOTRAUMA IN CHILDREN WITH ACUTE RESPIRATORY FAILURE
}

\author{
Olha Filyk \\ Department of Anesthesiology and Intensive Care \\ Danylo Halytsky Lviv National Medical University \\ 7 Chernihivska str., Lviv, Ukraine, 79010 \\ filyk_olha@meduniv.lviv.ua
}

\begin{abstract}
The aim of the study was to establish the prevalence of diaphragmatic dysfunction (DD), depending on the strategy of mechanical ventilation (MV).

Materials and methods. We completed the prospective single-center cohort study. Data analysis included 82 patients (1 month - 18 years old), divided into I group (lung-protective MV) and II group (diaphragm-protective in addition to lung-protective MV).

Patients were divided into age subgroups. Stages of the study: 1st day (d1), 3rd (d3), 5th (d5), 7th (d7), 9th (d9), 14th (d14), 28th (d28). We studied amplitude of diaphragm movement; thickening fraction, parameters of acid-base balance and MV. Results are described as median [IQR - interquartile range] with level of significance $\mathrm{p}$.

Results. In patients of the 1st age subgroup in I group there were episodes with under-assist during MV, while in II group diaphragm overload was registered only on d5.

In patients of 2nd subgroup in I group we found over-assist of MV with excessive work of the right hemidiaphragm and low contractions of left dome at all stages of study, while in II group - the only episode of diaphragmatic weakness on d3 due to under-assist of MV. In the 3rd subgroup the proper diaphragmatic activity in I group was restored significantly later than in II group. In 4th subgroup of I group there was episode of high work of diaphragm on d5, whereas in II group - all data were within the recommended parameters for diaphragm-protective strategy of MV. In 5th subgroup of I group excessive work of both right and left domes of diaphragm was significantly more often registered than in II group, however, in II group there were found episodes of both type changes - diaphragmatic weakness and excessive work.

Conclusion. The prevalence and variety of manifestations of DD depend on the strategy of MV. Low incidence of DD was associated with lower duration of MV: in 1st age subgroup in 1.5 times; in 2nd age subgroup - in 2.4 times; in 4th age subgroup in 1.75 times; in 5th age subgroup - in 4.25 times.
\end{abstract}

Keywords: diaphragm, mechanical ventilation, children.

DOI: $10.21303 / 2504-5679.2020 .001414$

\section{Introduction}

Diaphragm weakness is highly prevalent in critically ill patients. It may exist prior to ICU admission and may precipitate the need for mechanical ventilation but it also frequently develops during the ICU stay $[1,2]$. In addition, severe weakness of the diaphragm is frequent in mechanically ventilated patients, in whom it contributes to poor outcomes including increased mortality [3, 4]. And taking into account that from $30 \%$ to $64 \%$ of children in PICU need mechanical ventilation (MV), this clinical issue is highly important nowadays [5].

The described problem can be solved with reducing the incidence of diaphragmatic dysfunction and maintaining normal ranges both amplitude of diaphragm movement and its thickening fraction during MV. It will be possible with careful titration of mechanical ventilation parameters and taking into account data of diaphragm function for each patient individually.

The aim of the study was to establish the prevalence of diaphragmatic dysfunction, which might lead to diaphragm damage in children with acute respiratory failure, depending on the strategy of mechanical ventilation.

\section{Materials and methods}

From January 2018 to April 2020 we completed the prospective single-center cohort study at the Department of Anesthesiology and Intensive Care, Danylo Halytsky Lviv National Medical University; Department of Anesthesiology and Intensive Care, Lviv Regional Children Hospital 
"OCHMATDYT". We included patients with acute respiratory failure who was mechanically ventilated for more than 3 days. Exclusion criteria for the study were: the refusal of the patient's legal representatives to participate in the study at any of its stages, the patient's agonizing state upon admission, and the onset of MV less than $48 \mathrm{~h}$ after prior weaning.

The study was conducted in accordance with the requirements of good clinical practice, the Council of Europe Convention on Human Rights and Biomedicine, the Helsinki Declaration of the World Medical Association. The study was approved by the Bioethics Commission of Danylo Halytsky Lviv National Medical University, protocol №1, January 30, 2018. All patients` relatives or their legal representatives signed informed consent to participate in the study.

The study included 89 patients aged 1 month - 18 years. All patients were randomly divided into 2 groups (using random.org). Group I included patients who received lung-protective ventilation strategy, group II - patients who received diaphragm-protective in addition to lung-protective ventilation strategy. 82 patients were included in the data analysis. We studied indicators of diaphragm function (amplitude of diaphragm movement and it was considered that decreasing of this indicator less than $8 \mathrm{~mm}$ was a marker of under-assistance during MV and increasing of this indicator over $15 \mathrm{~mm}$ was a marker of over-assistance during $\mathrm{MV}$; thickening fraction and it was considered that decreasing of this indicator less than $15 \%$ was a marker of diaphragm weakness; increasing it up to more than $35 \%$ was a marker of high respiratory function and a potentially damaging factor for diaphragm), parameters of acid-base balance and mechanical ventilation.

To assess age-dependent data, patients were divided into age subgroups: 1 subgroup - children 1 month - 1 year; 2nd subgroup - children 1-3 years; 3 subgroup - children 3-6 years; 4 subgroup - children 6-13 years; 5 subgroup - children 13-18 years.

Stages of the study: 1st day (d1), 3rd day (d3), 5th day (d5), 7th day (d7), 9th day (d9), 14th day (d14), 28th day (d28).

Results described in this article is the part of the clinical study "Diaphragm ultrasound and trends in electrolyte disorders and transthyretin level as a method to predict ventilation outcome in children: the prospective observational cohort study"; ISRCTN84734652.

Statistical analysis of the study results was performed using MS Excel 2017 with the calculation median [IQR - interquartile range], the level of significance p with Kruskal-Wallis test.

\section{Results}

According to thickening fraction of diaphragm, we identified age-specific features in children during MV: in patients of the first age subgroup in I group there were found weakness of right hemidiaphragm with compensatory excessive level of work for its left dome on dland $\mathrm{d} 9$, on the other hand, in group II diaphragm overload was registered only at stage d5.

The amplitude of right hemidiaphragm movements (Fig. 1) had no significant differences between I and II groups of $1^{\text {st }}$ age subgroup at all stages of the study $(p>0.05)$, however, we observed a tendency to its gradually increasing from $3.5[3.1 ; 4.5] \mathrm{mm}$ on d1 to $12.4[10.2 ; 12.9] \mathrm{mm}$ on $\mathrm{d} 9$ in I group, and from $4.5[3 ; 5] \mathrm{mm}$ to $8.9[6.8 ; 9.5] \mathrm{mm}$ at the same stage in II group of patients.

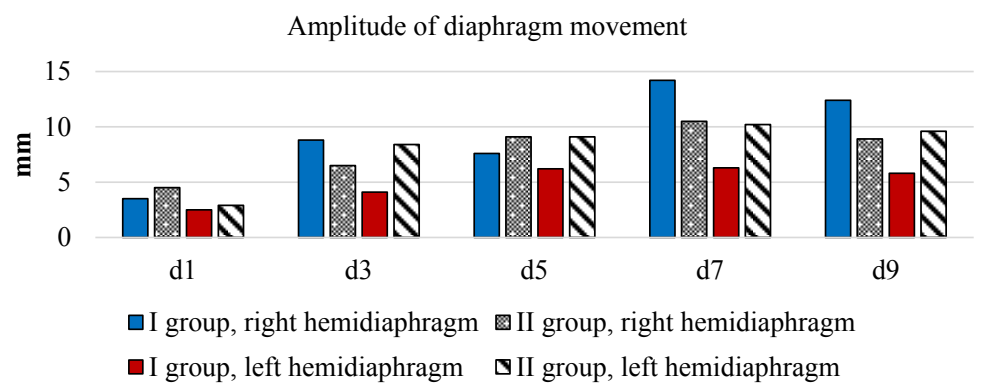

Fig. 1. The amplitude of right and left hemidiaphragm movement in $1^{\text {st }}$ age subgroup of patients

At the same time, the amplitude of movements of left hemidiaphragm in $1^{\text {st }}$ age subgroup increased and was significantly higher in II group on $\mathrm{d} 3$ with data 8.4 [7.3; 9.6] $\mathrm{mm}$ in comparison 
with $4.1[3.8 ; 4.5] \mathrm{mm}$ in group I $(\mathrm{p}=0.04)$, and on $\mathrm{d} 9$ it was $9.6[8.2 ; 12.2] \mathrm{mm}$ in II group and $5.8[4.1 ; 8.9] \mathrm{mm}$ in I group $(\mathrm{p}=0.03)$.

In patients of 2 nd age subgroup changes in I group were opposite to described previously we found excessive work of the right hemidiaphragm with low contractions of left dome at all stages of study, while in II group - it was the only episode of diaphragmatic weakness on stage d3.

The amplitude of movements of the right hemidiaphragm (Fig. 2) in $2^{\text {nd }}$ age subgroup had no significant differences between I and II groups at all stages of study. We found a tendency to gradually increase these indicators from stage d1 to stage d9. Data on the amplitude of movements of the left hemidiaphragm showed significant differences on $\mathrm{d} 3$ and $\mathrm{d} 5$ in patients of II group, and it was associated with inspiratory time decreasing on the same stages.

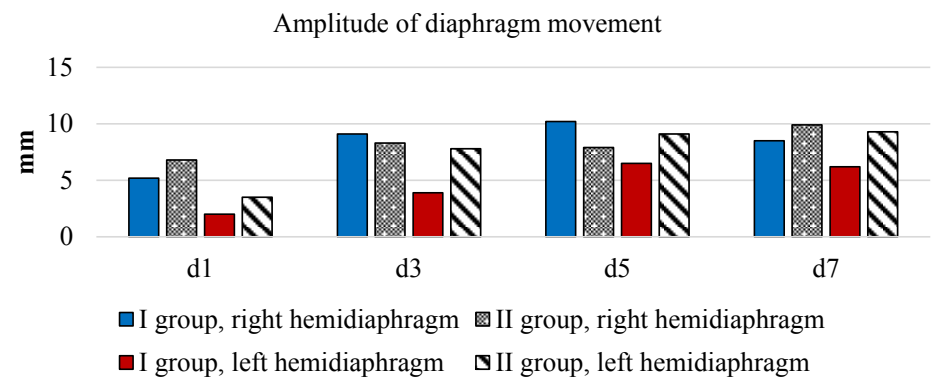

Fig. 2. The amplitude of right and left hemidiaphragm movement in $2^{\text {nd }}$ age subgroup of patients

Thus, the amplitude of movements of left hemidiaphragm on $\mathrm{d} 3$ was $3.9[2.5 ; 4.1] \mathrm{mm}$ with inspiratory time $0.7 \pm 0.1$ seconds in I group, in comparison with the amplitude 7.8 [3.8; 9.2] mm $(\mathrm{p}=0.01)$ and inspiratory time $0.45 \pm 0.01$ seconds $(\mathrm{p}=0.02)$ in II group. Subsequently, inspiratory time in II group did not change until d9, and the amplitude of movements of left hemidiaphragm increased significantly in comparison with I group of patients on $\mathrm{d} 5(9.1[8.5 ; 10] \mathrm{mm}$ in II group, and $6.5[5 ; 7.4] \mathrm{mm}$ in I group, $\mathrm{p}=0.05$.

In 3rd age subgroup, II group spontaneous diaphragm activity was restored significantly earlier from d1, and the fraction of thickening of right dome in this group was $19.4[15.2 ; 21.4] \%$ in comparison with the absence of contractions in I group $(\mathrm{p}=0.001)$. Similar situation was with left dome of diaphragm, when on $\mathrm{d} 1$ in I group it was in normal range, when in II group $15.4[6.5 ; 18] \%(p=0.01)$. On $d 3$, increasing of the thickening fraction of right and left domes of diaphragm were found significantly earlier among patients of II group, where the data were 24.5 $[22,7 ; 31.5] \%$ for right dome and 25.6 [22.51 28.3] \% for left dome, compared to 12 [9.4; 14.2] \% for right and $18[11.8 ; 21] \%$ for left dome in I group $(p=0.01$ and $p=0.03)$. From d5 to $d 9$, the diaphragm thickening fraction in both groups was within the range recommended by the diaphragm-protective ventilation strategy. Summarizing all the above in 3rd age subgroup the proper diaphragmatic activity in I group of patients was restored later than in II group.

There were no significant differences between I and II groups of patients of 3rd age subgroup in amplitude of right dome of diaphragm movements (Fig. 3). Whereas for the left dome of the diaphragm, this data were significantly higher in II group on d7 and d9, it was associated with inspiratory time decreasing same stages.

In I group of $4^{\text {th }}$ age subgroup there were found significantly higher fraction of thickening of both right and left domes of diaphragm on d5: for right dome it was $53.25[26,5 ; 80] \%$ compared to $31.3[30.4 ; 35.7] \%$ in II group; and $53.1[41.7 ; 58.4] \%$ in I group compared to 40.55 [22.2; 48.9] \% in I group for the left dome of diaphragm $(\mathrm{p}=0.02$ and $\mathrm{p}=0.02)$.

In addition, there were significantly higher amplitude of movements of both domes of diaphragm on d5 (Fig. 4): for the right dome it was 15.9 [14.6; 19.5] $\mathrm{mm}$ in group I, compared with $8.1[7.5 ; 9.7] \mathrm{mm}$ in group II ( $\mathrm{p}=0.04)$; for the left dome of diaphragm $-22[21,5 ; 23.5] \mathrm{mm}$ in group I and $12[9.5 ; 14] \mathrm{mm}$ in group II $(\mathrm{p}=0.001)$.

In the 5th age subgroup in I group excessive work of both right and left domes of diaphragm was significantly more often registered during weaning than in II group, however, in II group were 
found episodes of both type changes - diaphragmatic weakness and excessive work. The indicators of the diaphragm thickening fraction were high and exceeded the limits recommended for the diaphragm-protective strategy of ventilation in II group of patients on $\mathrm{d} 1, \mathrm{~d} 3$ and $\mathrm{d}$ : for right dome of the diaphragm it were $44.25[35.7 ; 52.8] \%$ compared to $25[20.9 ; 30] \%$ in group I ( $\mathrm{p}=0.02)$ on d1; and 68.05 [66.7; 69.4] \% compared to 18.05 [7.5; 60.7] \% on d3 ( $\mathrm{p}=0.001)$. On $\mathrm{d} 7$ in I group they were $54.6[28.6 ; 80.6] \%$ compared to $31.6[23.5 ; 32.4] \%$ in II group $(p=0.001)$. The values of the thickening fraction of left diaphragm dome were also high on $\mathrm{d} 1, \mathrm{~d} 3$ and $\mathrm{d} 7$.

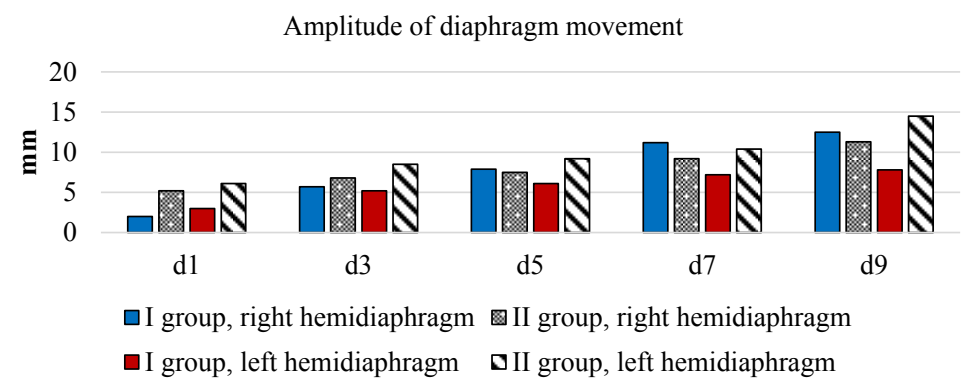

Fig. 3. The amplitude of right and left hemidiaphragm movement in $3^{\text {rd }}$ age subgroup of patients

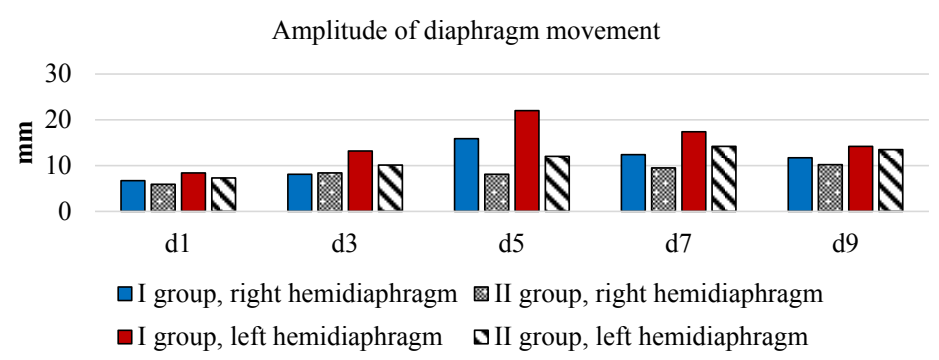

Fig. 4. The amplitude of right and left hemidiaphragm movement in $4^{\text {th }}$ age subgroup of patients

The amplitude of diaphragm movements (Fig. 5) was below the recommended minimum value of $8 \mathrm{~mm}$ in both groups of patients till $\mathrm{d} 5$, and among patients of I group on $\mathrm{d} 7$ for the right and left domes, this data exceeded the recommended values $15 \mathrm{~mm}$ and was 18.1 [8.9; 21.9] $\mathrm{mm}$ for right dome and $18.5[16.3 ; 19.4] \mathrm{mm}$ for left dome, compared to $30.9[12.5 ; 49.3] \mathrm{mm}$ and $12.5[11.2 ; 15.3] \mathrm{mm}$ in II group. It was associated with a significantly higher inspiratory time in I group on these stages of the study.

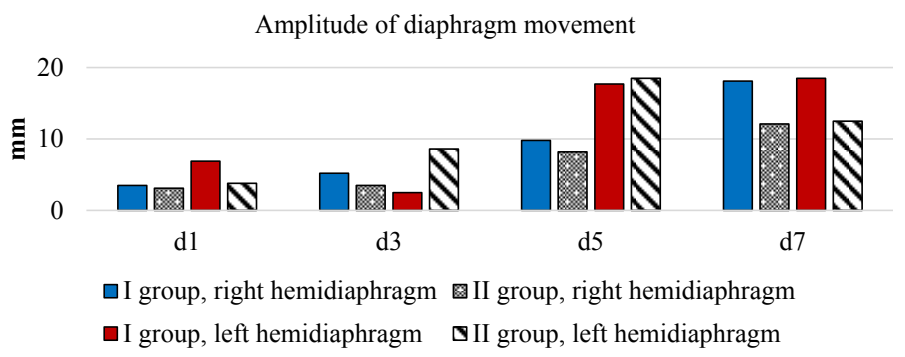

Fig. 5. The amplitude of right and left hemidiaphragm movement in $5^{\text {th }}$ age subgroup of patients

Thus, use of diaphragm-protective strategy of MV in patients of the 5th age subgroup lead to reducing number of days when excessive work of the diaphragm was observed and therefore to avoid possible damage of diaphragm.

\section{Discussion}

This study identified possible mechanisms of diaphragmatic myotrauma in mechanically ventilated children. It is well known, that success of weaning from MV depends on age and dura- 
tion of MV in children [6, 7]. On the other hand, as long we provide MV, as higher is the incidence of diaphragm atrophy and its weakness $[8,9]$. Also, it was established that brief periods phrenic nerve stimulation (can improve mitochondrial function in the human diaphragm following MV [10]. Therefore, it is highly important to achieve normal function of diaphragm despite temporary life-saving respiratory support like MV. It might be implemented as diaphragm-protective strategy of MV [11, 12].

There are a lot of studies dedicated DD in adults discussing problem of acquired diaphragm dysfunction and its negative clinical impact on weaning outcome, length of mechanical ventilation (MV), survival and long-term outcome [13-16]. However, there are very little researches dedicated this issue among children. At the same time, criteria and tools for DD identification are the same for adult and children [17-19]. Moreover, pathophysiologically diaphragm-protective strategy in children is supported by recommendation to promote spontaneous breathing wherever its possible [20].

We found age-specific features of diaphragm dysfunction during MV in children: in $1^{\text {st }}$ age subgroup I group there were episodes with under-assist during MV, which lead to weakness for right hemidiaphragm with compensatory excessive work for left its dome both at the beginning and at the end of MV. While in II group diaphragm overload was registered only on $\mathrm{d} 5$ and it might be due to over-assist during MV. It is interesting, that there are not precise cut off values that define safe ranges for inspiratory effort for adults [12]. Apart from this, safe thresholds of diaphragm activity to avoid under-assistance are absent. These limits are likely to vary per person depending on diaphragm strength. Nevertheless, common parameters that are used to define under-assistance are available and, as we proposed in our study, under-assist means thickening fraction of diaphragm have to be less than $10 \%$, while for over-assist - exceed $30 \%$ [12].

In patients of $2^{\text {nd }}$ age subgroup I group changes were the opposite to previous described - we found over-assist of MV with excessive work of the right hemidiaphragm with low contractions of left dome at all stages of study in I group, while in II group - the only episode of diaphragmatic weakness in stage $\mathrm{d} 3$ due to under-assist of MV.

In the 3rd age subgroup the proper diaphragmatic activity in I group of patients was restored later than in II group, therefore this patients need full assist with MV during this time. Goligher EC with colleagues (2015) and Schepens T et all., (2020) established, that unloading of diaphragm, more than the effects of MV itself, results in disuse atrophy and weakness. This is called overassistance myotrauma and affects about $50 \%$ of patients receiving MV [12, 21, 22].

In the 4th age subgroup in I group there was episode of high work of a diaphragm at stage d5, which means over-assist with MV at this stage, whereas in II group - all data of diaphragm function were within the recommended parameters for diaphragm-protective strategy of MV at all stages of our study. So, in this age subgroup in II group it was achieved diaphragm-protective strategy during whole time of MV.

In the 5th age subgroup in I group excessive work of both right and left domes of diaphragm was significantly more often registered during weaning than in II group, however, in II group were found episodes of both type changes - diaphragmatic weakness and excessive work.

It was found that lower incidence of diaphragmatic dysfunction lead to decreasing duration of mechanical ventilation: in patients of the 1st age subgroup by 1.5 times $(p=0.08)$; in patients of 2 nd age subgroup - by 2.4 times $(p=0.18)$; in 4th age subgroup - by 1.75 times $(p=0.1)$; in 5 th age subgroup - by 4.25 times $(\mathrm{p}=0.009)$. In patients of 3 rd age subgroup duration of mechanical ventilation increased by 1.1 times $(\mathrm{p}=0.68)$. The frequency of complications (reintubations) was reduced in 1st age subgroup by 4.3 times ( $p=0.02)$; in 2 nd age subgroup - by 3.4 times $(p=0.04)$. There were no significant differences in the frequency of tracheostomy among patients of I and II groups.

Limitations of the study. Our current study has several limitations. First, neither results assessor nor medical staff, who take care for patients, could not be blinded to group allocation because of the nature of the study. Second, the number of patients, who were included in the study, have to be enlarged in order to achieve significant differences in data which we studied.

Prospects for further research. Further studies are required to evaluate whether diaphragm-protective MV might improve clinical outcomes (length of stay in ICU, 28-days mortality 
rate) in all age subgroups of children. In addition, it will be highly important to implement into clinical practice the rehabilitation of such patients.

\section{Conclusion}

1. The prevalence and variety of manifestations of DD depend on the strategy of MV. Diaphragm-protective strategy reduced the incidence of DD.

2. In case of diaphragm-protective MV the incidence of under-assist and over-assist in 1st, 2nd, 4th and 5th subgroups were low, while in 3rd subgroup - restoration of adequate spontaneous breathing occurs earlier.

3. Low incidence of DD in II group was associated with lower duration of MV: in 1st age subgroup in 1.5 times; in 2nd age subgroup - in 2.4 times; in 4th age subgroup - in 1.75 times; in 5 th age subgroup - in 4.25 times. In patients of 3rd age subgroup duration of MV was increased in 1.1 times.

\section{References}

[1] Goligher, E. C., Brochard, L. J., Reid, W. D., Fan, E., Saarela, O., Slutsky, A. S. et. al. (2019). Diaphragmatic myotrauma: a mediator of prolonged ventilation and poor patient outcomes in acute respiratory failure. The Lancet Respiratory Medicine, 7 (1), 90-98. doi: http://doi.org/10.1016/s2213-2600(18)30366-7

[2] Dres, M., Goligher, E. C., Heunks, L. M. A., Brochard, L. J. (2017). Critical illness-associated diaphragm weakness. Intensive Care Medicine, 43 (10), 1441-1452. doi: http://doi.org/10.1007/s00134-017-4928-4

[3] Petrof, B. J., Hussain, S. N. (2016). Ventilator-induced diaphragmatic dysfunction: what have we learned? Current opinion in critical care, 22 (1), 67-72. doi: http://doi.org/10.1097/mcc.0000000000000272

[4] Shi, Z.-H., Jonkman, A., de Vries, H., Jansen, D., Ottenheijm, C., Girbes, A. et. al. (2019). Expiratory muscle dysfunction in critically ill patients: towards improved understanding. Intensive Care Medicine, 45 (8), 1061-1071. doi: http://doi.org/10.1007/ s00134-019-05664-4

[5] Dres, M., Jung, B., Molinari, N., Manna, F., Dubé, B.-P., Chanques, G. et. al. (2019). Respective contribution of intensive care unit-acquired limb muscle and severe diaphragm weakness on weaning outcome and mortality: a post hoc analysis of two cohorts. Critical Care, 23 (1). doi: http://doi.org/10.1186/s13054-019-2650-Z

[6] Abdo, M., Talat, M., Zamzam, S. (2014). Difficult weaning from mechanical ventilation in the pediatric ICU. Ain-Shams Journal of Anaesthesiology, 7 (1), 76-79. doi: http://doi.org/10.4103/1687-7934.128423

[7] Fontela, P. S., Piva, J. P., Garcia, P. C., Bered, P. L., Zilles, K. (2005). Risk factors for extubation failure in mechanically ventilated pediatric patients. Pediatric Critical Care Medicine, 6 (2), 166-170. doi: http://doi.org/10.1097/01.pcc.0000154922.65189.48

[8] Goligher, E. C., Dres, M., Fan, E., Rubenfeld, G. D., Scales, D. C., Herridge, M. S. et. al. (2018). Mechanical Ventilation-induced Diaphragm Atrophy Strongly Impacts Clinical Outcomes. American Journal of Respiratory and Critical Care Medicine, 197 (2), 204-213. doi: http://doi.org/10.1164/rccm.201703-0536oc

[9] Johnson, R. W., Ng, K. W. P., Dietz, A. R., Hartman, M. E., Baty, J. D., Hasan, N. et. al. (2018). Muscle atrophy in mechanically-ventilated critically ill children. PLOS ONE, 13 (12), e0207720. doi: http://doi.org/10.1371/journal.pone.0207720

[10] Martin, A. D., Joseph, A.-M., Beaver, T. M., Smith, B. K., Martin, T. D., Berg, K. et. al. (2014). Effect of Intermittent Phrenic Nerve Stimulation During Cardiothoracic Surgery on Mitochondrial Respiration in the Human Diaphragm. Critical Care Medicine, 42 (2), e152-e156. doi: http://doi.org/10.1097/ccm.0b013e3182a63fdf

[11] Schepens, T., Dres, M., Heunks, L., Goligher, E. C. (2019). Diaphragm-protective mechanical ventilation. Current Opinion in Critical Care, 25 (1), 77-85. doi: http://doi.org/10.1097/mcc.0000000000000578

[12] Schepens, T., Dianti, J. (2020). Diaphragm protection: what should we target? Current Opinion in Critical Care, 26 (1), 35-40. doi: http://doi.org/10.1097/mcc.0000000000000683

[13] Dubé, B.-P., Dres, M. (2016). Diaphragm Dysfunction: Diagnostic Approaches and Management Strategies. Journal of Clinical Medicine, 5 (12), 113. doi: http://doi.org/10.3390/jcm5120113

[14] Demoule, A., Jung, B., Prodanovic, H., Molinari, N., Chanques, G., Coirault, C. et. al. (2013). Diaphragm Dysfunction on Admission to the Intensive Care Unit. Prevalence, Risk Factors, and Prognostic Impact - A Prospective Study. American Journal of Respiratory and Critical Care Medicine, 188 (2), 213-219. doi: http://doi.org/10.1164/rccm.201209-1668oc

[15] Dres, M., Dubé, B.-P., Mayaux, J., Delemazure, J., Reuter, D., Brochard, L. et. al. (2017). Coexistence and Impact of Limb Muscle and Diaphragm Weakness at Time of Liberation from Mechanical Ventilation in Medical Intensive Care Unit Patients. American Journal of Respiratory and Critical Care Medicine, 195 (1), 57-66. doi: http://doi.org/10.1164/rccm. 201602-0367oc 
[16] Medrinal, C., Prieur, G., Frenoy, É., Robledo Quesada, A., Poncet, A., Bonnevie, T. et. al. (2016). Respiratory weakness after mechanical ventilation is associated with one-year mortality - a prospective study. Critical Care, 20 (1). doi: http://doi.org/ 10.1186/s13054-016-1418-y

[17] DiNino, E., Gartman, E. J., Sethi, J. M., McCool, F. D. (2013). Diaphragm ultrasound as a predictor of successful extubation from mechanical ventilation. Thorax, 69 (5), 431-435. doi: http://doi.org/10.1136/thoraxjnl-2013-204111

[18] Kim, W. Y., Suh, H. J., Hong, S.-B., Koh, Y., Lim, C.-M. (2011). Diaphragm dysfunction assessed by ultrasonography: Influence on weaning from mechanical ventilation. Critical Care Medicine, 39 (12), 2627-2630. doi: http://doi.org/10.1097/ ccm.0b013e3182266408

[19] Carámbula, A., Visca, A., D’Amico, S., Angulo, M. (2019). Evaluación muscular respiratoria y periférica en la Unidad de Cuidados Intensivos. Archivos de Bronconeumología, 55 (5), 258-265. doi: http://doi.org/10.1016/j.arbres.2018.09.002

[20] Kneyber, M. C. J., de Luca, D., Calderini, E., Jarreau, P.-H., Javouhey, E. et. al. (2017). Recommendations for mechanical ventilation of critically ill children from the Paediatric Mechanical Ventilation Consensus Conference (PEMVECC). Intensive Care Medicine, 43 (12), 1764-1780. doi: http://doi.org/10.1007/s00134-017-4920-z

[21] Goligher, E. C., Fan, E., Herridge, M. S., Murray, A., Vorona, S., Brace, D. et. al. (2015). Evolution of Diaphragm Thickness during Mechanical Ventilation. Impact of Inspiratory Effort. American Journal of Respiratory and Critical Care Medicine, 192 (9), 1080-1088. doi: http://doi.org/10.1164/rccm.201503-0620oc

[22] Schepens, T., Verbrugghe, W., Dams, K., Corthouts, B., Parizel, P. M., Jorens, P. G. (2015). The course of diaphragm atrophy in ventilated patients assessed with ultrasound: a longitudinal cohort study. Critical Care, 19 (1). doi: http://doi.org/10.1186/ s13054-015-1141-0

\title{
CYTOKERATIN-18 AS A MARKER OF NON-ALCOHOLIC FATTY LIVER DISEASE IN OBESE ADOLESCENTS
}

\author{
Margaryta Khomenko \\ Department of Adolescent Medicine \\ Kharkiv Medical Academy of Postgraduate Education \\ 58 Amosova str., Kharkiv, Ukraine, 61000 \\ kh.margaryta@gmail.com
}

\begin{abstract}
In parallel with the obesity epidemic in the world, the prevalence of non-alcoholic fatty liver disease among children and adolescents is growing. Current data suggest that insulin resistance is one of the main factors in the pathogenesis of non-alcoholic fatty liver disease, and the content of fragments of caspase-cleaved cytokeratin-18 in the blood serum may be one of the informative indicators of non-alcoholic fatty liver disease progression.

The aim. To determine mechanisms of formation and progression of non-alcoholic fatty liver disease in obese children and adolescents by evaluating the level of cytokeratin-18.

Materials and methods. The study involved 46 adolescents with obesity and non-alcoholic fatty liver disease aged 12 17 years: 19 boys (41.3\%) and 27 girls (58.7\%). Clinical (weight, height, waist and hip circumference), laboratory (glucose, immunoreactive insulin, lipid metabolism, alanine aminotransferase, aspartate aminotransferase, gamma-glutamyl transpeptidase, cytokeratin-18) parameters were studied and instrumental examination (abdominal ultrasound) was performed. To assess insulin resistance the triglyceride-glucose index was calculated.

Results. Depending on the presence of insulin resistance patients were divided into two groups: 21 (45.7\%) of adolescents with insulin resistance and 25 (54.3\%) of adolescents without insulin resistance. Blood tests in patients with insulin resistance revealed significantly higher levels of total cholesterol, triglycerides, very low-density lipoprotein cholesterol, fasting immunoreactive insulin, cytokeratin-18 and gamma-glutamyl transpeptidase. All adolescents were divided into 2 groups depending on the level of cytokeratin-18: patients with cytokeratin-18 $>233 \mathrm{mIU} / \mathrm{ml}$ and $<233 \mathrm{mIU} / \mathrm{ml}(15$ (32.6 \%) and 31 (67.4 \%)
\end{abstract}

